\title{
Disparities in compliance of treatment in patients with osteosarcoma
}

\author{
Alfonso Pérez-Bañuelos ${ }^{1}$, Miguel Á. Palomo-Colli2* ${ }^{*}$ Stanislaw Sadowinski-Pine ${ }^{3}$, Mónica Mier-Cabrera ${ }^{4}$, \\ José F. Gaytán-Morales ${ }^{5}$ and Luis E. Juárez-Villegas ${ }^{5}$ \\ ${ }^{1}$ Oncology Department, Hospital Infantil Teletón Oncología, Santiago de Querétaro, Qro.; ${ }^{2}$ Oncology Department, Hospital Infantil de México Federico \\ Gómez, Mexico City; ${ }^{3}$ Pathology Department, Hospital Infantil de México Federico Gómez, Mexico City; ${ }^{4}$ Oncology Department, Ixtapaluca High \\ Specialty Regional Hospital, State of Mexico; ${ }^{5}$ Oncology Department, Hospital Infantil de México Federico Gómez, Mexico City. Mexico
}

\begin{abstract}
Introduction: Long-term survival rates in osteosarcoma had improved because of neoadjuvant chemotherapy and multimodal therapy. Dose intensity is a factor than can determine outcome in cancer patients. Objective: Evaluate adherence to international osteosarcoma treatment protocols and dose intensity in a pediatric population. Patients and methods: We analyzed 34 medical records of pediatric patients with osteosarcoma between the year 2009 and 2014. The relative dose intensity (RDI) was estimated by dividing each drug dose/the time (days) between day 1 of chemotherapy and the surgery. After that we compared it with the planned dose intensity. Results: Thirty-two patients were included, 13 of them were treated with cisplatin (CDDP)/adriamycin (ADR)/methotrexate and 19 with CDDP/ADR. The RDI average was $0.65 \pm 0.21 \%$ and the median of time between day 1 of chemotherapy and surgery was $19.25 \pm 8.54$ weeks. Local control surgery was rejected by $23.5 \%$ of patients. Local control surgery was practiced in 23 patients, of which $34.7 \%$ reported more than $90 \%$ of necrosis. Conclusions: Dose intensity is not suitable in this group of patients, which is reported around $85 \%$ in international treatment protocols. About surgery, in our patients, it was not practiced on recommended time. Some identified factors in our population that avoid the treatment adherence were: reject to radical surgery, economical issues and overcrowded healthy system.
\end{abstract}

Key words: Chemotherapy. Dose intensity. Osteosarcoma. Children. Compliance.

\section{Disparidades en el cumplimiento de los protocolos de tratamiento en pacientes con osteosarcoma}

\section{Resumen}

Introducción: La supervivencia en osteosarcoma (OS) ha mejorado debido a la quimioterapia prequirúrgica y el tratamiento multimodal. La intensidad de dosis es un factor que puede modificar la supervivencia. Objetivo del estudio: Evaluar la adherencia a los protocolos de tratamiento en OS y la intensidad de dosis en niños. Material y métodos: Se revisaron los expedientes de pacientes con OS del año 2009 al 2014. Se calculó la intensidad de dosis relativa (IDR), dividiendo la dosis de cada uno de los fármacos entre el tiempo comprendido entre el inicio del tratamiento y la cirugía (IDC), posteriormente comparando con la intensidad de dosis planeada. Resultados: Treinta y dos pacientes fueron incluidos, 13 recibieron cisplatino (CDDP)/adriamicina (ADR)/metotrexato y 19 CDDP/ADR. La media de IDR fue de $0.65 \pm 0.21 \%$ y el IDC medio de $19.25 \pm 8.54$ semanas. El $23.5 \%$ de los pacientes rechazaron la cirugía. A 23 se les realizó cirugía de control local, el $34.7 \%$ de ellos tuvieron buena necrosis ( $\geq 90 \%$ ). Conclusiones: La intensidad de dosis no es adecuada en este grupo de pacien-

Correspondence:

*Miguel Á. Palomo-Collì

E-mail: phalomi@ hotmail.com
Date of reception: 09-06-2019

Date of acceptance:26-05-2020

DOI: 10.24875/j.gamo.M20000202
Available online: 11-12-2020 Gac Mex Oncol. 2020;19(4):1-6 www.gamo-smeo.com 1665-9201/@ 2020 Sociedad Mexicana de Oncología. Published by Permanyer. This is an open access article under the terms of the CC BY-NC-ND license (http://creativecommons.org/licenses/by-nc-nd/4.0/). 
tes; la cual se reporta en protocolos internacionales del $85 \%$ o más. En nuestros pacientes la cirugía no se practicó en el tiempo recomendado. Algunos factores identificados en nuestra población que evitan la adherencia al tratamiento fueron: rechazo a la cirugía radical, problemas económicos y sistema de salud sobrepoblado.

Palabras clave: Quimioterapia. Intensidad de dosis. Osteosarcoma. Niños. Cumplimiento.

\section{Introduction}

Osteosarcoma (OS) is the most common primary malignant bone tumor in pediatrics. With chemotherapy, two thirds of patients with non-metastatic OS will live, which implies chemotherapy success in micrometastases eradication. Surgery is the cornerstone of treatment, but it is not curative by itself. Pre-treatment factors that influence the result are: location, size of the primary tumor and metastatic disease ${ }^{1-7}$.

In 1970, adriamycin (ADR) and methotrexate (MTX) were the first drugs to be used. Cisplatin (CDDP) and ifosfamide were subsequently added, with a significant improvement in 5-year disease-free survival (DFS). Timely surgery is recognized to be the most important factor-8.

Rosen introduced preoperative chemotherapy to eradicate micrometastases, reduce tumor burden and assess histological response to chemotherapy ${ }^{3,4}$. In patients with localized OS, response to preoperative chemotherapy was good ( $\geq 90 \%$ of necrosis) in $59 \%$. Prognosis was significantly correlated with histological response: 5 -year overall survival rate was $68 \%$ in good responders and $52 \%$ in poor responders $(p=0.0001)^{9}$. After neoadjuvant chemotherapy, the factors that influence the outcome are surgical resectability and the degree of tumor necrosis ${ }^{10}$.

The European and American Osteosarcoma Studies (EURAMOS) group administers 10 weeks of neoadjuvant chemotherapy with MAP (MTX, ADR and CDDP) ${ }^{11}$. Preoperative chemotherapy was completed in $94 \%$ of patients. At definitive surgery, $50 \%$ of patients had at least $90 \%$ of necrosis ${ }^{12}$.

Bacci suggested that ADR dose was the most important factor in the regimen. Subsequently, he arrived to the conclusion that MTX peak serum level has significantly influenced the percentage of tumor necrosis ${ }^{13-15}$.

Various methods have been used to calculate dose intensity in chemotherapy regimens. In 1991, Longo compared these methods and offered a guideline of mathematical formulas for dose intensity calculation ${ }^{16,17}$.

Hryniuk and Bush defined the importance of dose intensity and created the concept of dose intensity, defined in $\mathrm{mg} / \mathrm{m}^{2} /$ week units of the drug. In 1990, Miller described the formula: $\left(d_{1}+d_{2}+d_{3}\right) /\left(3^{*} n_{1}\right)$, to individually calculate the dose intensity of each chemotherapy cycle. When comparing both methods in the same proto$\mathrm{col}$, the Hryniuk method was more effective in predicting treatment response $\mathrm{e}^{16-18}$.

Regarding OS, the relationship between dose intensity and histological response and survival is a topic of discussion. In 1998, Bacci analyzed the prognostic factors of histological response in patients with localized OS and concluded that the chondroblastic histological subtype and low serum MTX levels predict a poor histological response; he also concluded that intensifying neoadjuvant chemotherapy is not associated with histological response $\mathrm{e}^{19-21}$.

The Cooperative Osteosarcoma Study (COSS) Group failed to demonstrate that multiple drugs at higher dose intensities offer a higher DFS. However, multiple studies have recognized the relationship between MTX higher dose intensity and survival in patients with OS $^{22,23}$.

\section{Methods}

The objectives in this study were:

- To identify the intensity of neoadjuvant chemotherapy doses in patients diagnosed with OS.

- To evaluate compliance with the treatment protocols used in the treatment of children with OS with international protocols.

Retrospective, descriptive, observational study of patients diagnosed with OS at Federico Gómez Children's Hospital of Mexico from 2009 to 2014. Patients with de novo OS, younger than 18 years, who received treatment with neoadjuvant chemotherapy and that had complete data for the purposes of this study were included. Data related to the chemotherapy cycles administered during neoadjuvant treatment (protocol, number of cycles, and cycle administration frequency: weekly or every 21 days) were collected and analyzed. Gender, age, body surface area (BSA), primary tumor location and classification (localized or metastatic), type of performed surgery, and percentage of tumor necrosis were recorded. Dose intensities of each administered drug were calculated based on the Hryniuk method. Statistical analysis was carried out using the SPSS 18 package. Percentages were used for the 
description of qualitative variables, and the mean and standard deviation were used for numerical variables.

\section{Scheduled treatment}

Treatment consisted of surgery and preoperative and postoperative chemotherapy. Two chemotherapy regimens were used at the hospital, which were established in relation to the year and update of the treatment protocols established by the institution. The CDDP/ADR treatment regimen used the following doses: CDDP $120 \mathrm{mg} / \mathrm{m}^{2}$ BSA and ADR at $75 \mathrm{~m} / \mathrm{gm}^{2}$ BSA every 3 weeks (21 days) administered on weeks $0,3,6$ and 9 . The MAP regimen used CDDP at $120 \mathrm{mg} / \mathrm{m}^{2} \mathrm{BSA}$ and ADR at $75 \mathrm{mg} / \mathrm{m}^{2} \mathrm{BSA}$ on weeks 1 and 6 , high-dose MTX at $12 \mathrm{~g} / \mathrm{m}^{2}$ BSA with folinic acid rescue on weeks 4, 5, 9 and 10 .

\section{Dose intensity: evaluation of the received treatment}

- Planned Dose Intensity (PDI):

Total dose of the drug according to

the chemotherapy protocol

Time defined by the protocol from the start

of treatment to the day of surgery

- Calculated dose intensity (CDI):

Total dose received of the drug

Time elapsed from the start of treatment

to the day of surgery

- Relative Dose Intensity (RDI):

\section{Calculated dose intensity (CDI)}

Planned dose intensity (PDI)

Unit of measurement: milligrams or grams/square meter/week $\left(\mathrm{mg} / \mathrm{m}^{2} /\right.$ week).

The MAP regimen consists of two blocks divided in 10 weeks of treatment, neoadjuvant drugs PDI was: CDDP $240 \mathrm{mg} / \mathrm{m}^{2}$, ADR $150 \mathrm{mg} / \mathrm{m}^{2}$ and MTX $48 \mathrm{~g} / \mathrm{m}^{2}$; the time defined for surgery was week 11 after 2 treatment blocks (6 cycles). PDls calculated in weeks were: for CDDP at $24 \mathrm{mg} / \mathrm{m}^{2}$, weekly; for ADR at $15 \mathrm{mg} / \mathrm{m}^{2}$, weekly; and for MTX $4.8 \mathrm{~g} / \mathrm{m}^{2}$, weekly.

In the CDDP/ADR regimen, PDI was $480 \mathrm{mg} / \mathrm{m}^{2} / 300$ $\mathrm{mg} / \mathrm{m}^{2}$, respectively. Time to surgery was treatment week 12. PDI for CDDP was $40 \mathrm{mg} / \mathrm{m}^{2}$ weekly, and for ADR, $25 \mathrm{mg} / \mathrm{m}^{2}$ weekly.

In patients receiving a number of cycles other than 4, time was individually estimated. Treatment compliance
Table 1. Characteristics of the population of children with osteosarcoma

\begin{tabular}{|l|c|c|}
\hline Characteristic & No. & $\%$ \\
\hline Gender & & \\
$\quad$ Males & 22 & 64.7 \\
Females & 12 & 35.3 \\
\hline Age (years) & & \\
$\quad$ Mean & 11.5 & \\
Interval & $14-17)$ & \\
\hline Primary site & & \\
$\quad$ Distal femur & 13 & 38.2 \\
\hline Proximal humerus & 9 & 26.4 \\
\hline Proximal tibia & 6 & 17.7 \\
\hline Proximal femur & 2 & 5.9 \\
\hline Distal tibia & 1 & 2.9 \\
\hline Maxillary & 1 & 2.9 \\
\hline Proximal fibula & 1 & 2.9 \\
\hline Multiple sites & 1 & 2.9 \\
\hline Metastasis at diagnosis & & \\
\hline Lung & 15 & 44.1 \\
\hline Central nervous system & 0 & 0 \\
\hline No metastasis & 19 & 55.9 \\
\hline Total & 34 & 100 \\
\hline
\end{tabular}

Table 2. Drugs used for neoadjuvant chemotherapy (CT)

\begin{tabular}{|l|c|c|}
\hline & No. & $\%$ \\
\hline CDDP + ADR & 19 & 56 \\
\hline CDDP + ADR + MTX & 14 & 41 \\
No CT received & 1 & 3 \\
\hline
\end{tabular}

CDDP: cisplatin; ADR: adriamycin; MTX: methotrexate.

was considered if a cumulative relative dose intensity equal to or higher than $85 \%$ of that established by the treatment protocol was achieved, and if surgery was performed on the weeks established by the protocol \pm one week (weeks 11 to 12). Both criteria had to be met for this definition.

\section{Study results}

In the screening period, 34 patients were identified. Patient characteristics at diagnosis are described in table 1.

Of the 34 patients, 33 received at least one cycle of neoadjuvant chemotherapy; distribution of the drugs used are presented in table 2.

Nineteen patients received neoadjuvant chemotherapy with CDDP and ADR, seven received 4 cycles prior to surgery as planned. In six patients, surgery was 
Table 3. Dose intensity in the neoadjuvant setting

\begin{tabular}{|c|c|c|c|c|c|c|c|c|c|c|c|}
\hline \multirow[t]{2}{*}{ Patient } & \multicolumn{3}{|c|}{ CDDP } & \multicolumn{3}{|c|}{ ADR } & \multicolumn{3}{|c|}{ MTX } & \multirow[t]{2}{*}{ Time to SX (weeks) } & \multirow[t]{2}{*}{ Cumulative RDI } \\
\hline & CDI & PDI & RDI & CDI & PDI & RDI & CDI & PDI & RDI & & \\
\hline 1 & 14.87 & 24 & 0.62 & 9.29 & 15 & 0.62 & 2.85 & 4.80 & 0.62 & 16.14 & 0.62 \\
\hline 2 & 21.82 & 24 & 0.91 & 13.64 & 15 & 0.91 & 4.36 & 4.80 & 0.91 & 11.00 & 0.91 \\
\hline 3 & 18.46 & 24 & 0.77 & 11.54 & 15 & 0.77 & 3.69 & 4.80 & 0.77 & 13.00 & 0.77 \\
\hline 4 & 13.55 & 24 & 0.56 & 8.47 & 15 & 0.56 & 2.71 & 4.80 & 0.56 & 17.71 & 0.56 \\
\hline 5 & 19.09 & 24 & 0.80 & 11.93 & 15 & 0.80 & 3.82 & 4.80 & 0.80 & 12.57 & 0.80 \\
\hline 6 & 28.73 & 40 & 0.72 & 17.95 & 25 & 0.72 & 0.00 & 0 & 0.00 & 16.71 & 0.72 \\
\hline 7 & 19.88 & 40 & 0.50 & 12.43 & 25 & 0.50 & 0.50 & 0 & 0.50 & 24.14 & 0.50 \\
\hline 8 & 15.07 & 40 & 0.38 & 9.42 & 25 & 0.38 & 0.38 & 0 & 0.38 & 31.86 & 0.38 \\
\hline 9 & 20.24 & 40 & 0.51 & 12.65 & 25 & 0.51 & 1.01 & 0 & 1.01 & 23.71 & 0.51 \\
\hline 10 & 27.76 & 40 & 0.69 & 17.36 & 25 & 0.69 & 0.00 & 0 & 0.00 & 17.29 & 0.69 \\
\hline 11 & 28.47 & 40 & 0.71 & 17.80 & 25 & 0.71 & 0.00 & 0 & 0.00 & 16.86 & 0.71 \\
\hline 12 & 31.39 & 40 & 0.79 & 19.63 & 25 & 0.79 & 0.00 & 0 & 0.00 & 15.29 & 0.79 \\
\hline 13 & 10.12 & 40 & 0.25 & 6.33 & 25 & 0.25 & 0.51 & 0 & 0.51 & 23.71 & 0.25 \\
\hline 14 & 43.09 & 40 & 1.08 & 26.92 & 25 & 1.08 & 0.00 & 0 & 0.00 & 5.57 & 1.08 \\
\hline 15 & 34.99 & 40 & 0.88 & 21.88 & 25 & 0.88 & 0.00 & 0 & 0.00 & 6.86 & 0.88 \\
\hline 16 & 20.50 & 40 & 0.51 & 12.80 & 25 & 0.51 & 0.00 & 0 & 0.00 & 11.71 & 0.51 \\
\hline 17 & 11.20 & 40 & 0.28 & 7.00 & 25 & 0.28 & 0.37 & 0 & 0.37 & 32.14 & 0.28 \\
\hline 18 & 15.46 & 40 & 0.39 & 9.66 & 25 & 0.39 & 2.06 & 0 & 2.06 & 23.29 & 0.39 \\
\hline 19 & 32.07 & 40 & 0.80 & 20.04 & 25 & 0.80 & 0.00 & 0 & 0.00 & 18.71 & 0.80 \\
\hline 20 & 30.21 & 40 & 0.76 & 18.88 & 25 & 0.76 & 0.00 & 0 & 0.00 & 19.86 & 0.76 \\
\hline 21 & 33.33 & 40 & 0.83 & 20.83 & 25 & 0.83 & 0.00 & 0 & 0.00 & 18.00 & 0.83 \\
\hline 22 & 31.11 & 40 & 0.78 & 19.44 & 25 & 0.78 & 0.00 & 0 & 0.00 & 23.14 & 0.78 \\
\hline 23 & 19.28 & 40 & 0.48 & 12.05 & 25 & 0.48 & 0.00 & 0 & 0.00 & 43.57 & 0.48 \\
\hline
\end{tabular}

CDDP: cisplatin; ADR: adriamycin; MTX: methotrexate; SX: surgery; CDI: calculated dose intensity (mg/m²/wk.); PDI: planned dose intensity (mg/m²/wk.); RDI: relative dose intensity $\left(\mathrm{mg} / \mathrm{m}^{2} / \mathrm{wk}.\right)$.

Table 4. Type of surgery

\begin{tabular}{|l|c|c|}
\hline & No. & $\%$ \\
\hline Limb-salvage surgery & 9 & 26.5 \\
\hline Amputation & 15 & 44.1 \\
\hline No surgery & 10 & 29.4 \\
\hline - Rejection & 8 & \\
\hline - Withdrawal & 1 & \\
\hline - Death & 1 & \\
\hline
\end{tabular}

carried out prior to completing the planned chemotherapy: four patients received 2 cycles and two received 3 cycles.

As of 2014, treatment with the MAP regimen was introduced, whereby five patients received 2 MAP blocks (CDDP/ADR + MTX + MTX).

In the 23 cases that were reviewed for the evaluation, only one patient met the protocol compliance criterion, 22 patients did not comply with the established protocols, since they included more chemotherapy cycles than established or included drugs in the protocol when they should not be included: five received more cycles than planned. Six patients received MTX in the protocol that only included CDDP-ADR, four of them received one course and two received 2 courses, as reflected in
Table 5. Dose intensity and time to primary control surgery

\begin{tabular}{l|c|c|c|} 
& Mean & Range & SD \\
\hline Cumulative RDI & 0.65 & $(0.25-1.08)$ & 0.21 \\
Time to surgery* & 19.25 & $(5.57-43.57)$ & 8.54 \\
*Time expressed in weeks \\
RDI: relative dose intensity; SD: standard deviation
\end{tabular}

table 3 in the CDI section. Regarding the surgical procedure, only three patients underwent surgery at the established times (weeks 11-12); however only one met the criterion for compliance with the protocol. The types of surgery are described in Table 4.

The measurements of relative dose intensity variation and local control CDI are shown in table 5.

Of the 34 included patients, three were excluded: one refused treatment, one died due to toxicity (sepsis/myelosuppression) and one more discontinued the treatment after one cycle. Eight patients $(23.52 \%)$ refused surgical treatment once neoadjuvant chemotherapy was completed, six of them were lost to follow-up, and two were started on palliative care. The reasons to explain this situation were radical surgery refusal by the patient and/or family members. 


\section{Discussion}

Dose intensity was inadequate. The time between the CDI that was expected for patients who received MAP according to EURAMOS-1 is 11 weeks, and for those who received CDDP/ADR, 12 weeks. Of the 23 patients, only two of them underwent local control within the first 10 weeks; however, these were patients who underwent surgery after 2 CDDP/ADR cycles. In the five patients who received CDDP/ADR/MTX according to EURAMOS-1, mean time to surgery was $14.08 \pm 1.2$ weeks, with a range of 11 to 17.7 weeks. In those patients who received 4 or more CDDP/ADR courses, mean time to surgery was $23.21 \pm 1.96$ weeks, with a range of 15.29 to 43.57 weeks. The reasons that explain surgery delay were: the time surgical planning took, chemotherapy-related infectious complications and reluctance of patients and their families with regard to radical surgery.

The proportion of patients who delay or discontinue the treatment due to surgery rejection is high. The factors that influence on the type of recommended surgery are: patient age, anatomical location of the tumor, cultural factors, surgeon experience, expectations of the patient and his/her family, early and late surgical risks, and reconstruction inherent limitations. Surgical planning should also consider patient chemotherapy regimen and coincide with bone marrow recovery after the last scheduled course of preoperative chemotherapy. With careful preoperative planning, the patient can be prepared in order to reduce intraoperative and postoperative risks. With proper coordination, chemotherapy interruption is ideally brief, and therapy resumption can usually occur within 2 weeks after surgery ${ }^{8}$.

Multidisciplinary management is necessary in order to cover all aspects that influence on OS treatment, especially surgical planning. Coordination between the medical oncologist and the surgeon is essential; however, intervention of the psychology and social work team is also necessary.

Owing to the biology of OS, once neoadjuvant chemotherapy is completed we must avoid that more than permissible time elapses between the last cycle and the surgical event, since this can enable tumor growth, and it would not allow adequately estimating the response to chemotherapy, which is a factor that can have an impact on survival ${ }^{24}$.

We found that dose intensity is not appropriate in this study group. Some of the factors that we identified were overcrowding of services (lack of physical space in the chemotherapy infusion areas), patient and family decisions, and lack of coordination between the treating departments, as well as a lack of supplies to carry out local control (among them, we can mention the possibility of having a prosthesis available when local control is required); although, as previously mentioned, the proportion of patients in whom limb salvage is carried out is low, and the findings of this study allow detecting problems and offer an opportunity for improvement in optimizing surgery planning and taking advantage of the benefits of neoadjuvant chemotherapy.

To achieve survival rates such as those reported in world literature, higher integration of the multidisciplinary team is necessary, as well as good adherence to the established protocols and education of the patient and family members. Assessing factors related to sociocultural aspects of the included population that may contribute to treatment results was not a goal in this study. Studies for dose intensity retrospective analysis are not easy to perform due to the variability of patient cohorts, but it is ideal that they are consistently performed and with strict follow-up. An important group of patients receive chemotherapy that is additional to that planned in the neoadjuvant setting.

The factors that can influence on adherence to compliance and favor disparities are multiple, some of them related to the phase of patient development, such as adolescence, which is a period of great physical changes and brain maturation that should be considered one of the most important factors when planning a treatment that will impact on quality of life and modify this stage of development. Not surprisingly, this phase is characterized by experimentation with both constructive and destructive behavior. Studies in many areas of chronic disease have demonstrated that adolescents often neglect their care and rebel against the rules established during their childhood. Therefore, it is to be expected that adolescents diagnosed with a life-threatening disease, such as cancer, will sometimes fail to comply with their therapy. The path to be followed includes improving communication and full participation of these young people in the planning of their treatment, thus moving from compliance to agreement. Further improvements should be sought in medication, early recognition, and support for family or social problems, and in the use of a multidisciplinary team specific for adolescents ${ }^{25}$.

\section{Conclusions}

Despite the fact that we use the drugs that have been described in most international protocols, our dose intensity is suboptimal with regard to those defined in other protocols, and the times surgery is performed at 
are not those defined by international treatment protocols. We consider it necessary for coordination within the multidisciplinary team to be improved in order to achieve control of the primary site at the times estimated by international treatment protocols. The dropout frequency is high in our study population and, therefore, will have to establish strategies to promote better treatment adherence and improve our overall survival, trying to emphasize acceptance of the disease by patients in order to be able to improve survival rates and reflect an appropriate model of care at clinics attended by patients with bone tumors.

\section{Funding}

The authors did not receive any funding for carrying out this article.

\section{Conflict of interests}

The authors declare that they have no conflicts of interest.

\section{Ethical disclosures}

Protection of human and animal subjects. The authors declare that no experiments were performed on humans or animals for this research.

Confidentiality of data. The authors declare that they have followed the protocols of their work center on the publication of patient data.

Right to privacy and informed consent. The authors have obtained informed consent from the patients and/or subjects referred to in the article.

\section{References}

1. Mirabello L, Troisi RJ, Savage SA. Osteosarcoma incidence and survival rates from 1973 to 2004: data from the Surveillance, Epidemiology, and End Results Program. Cancer. 2009;115:1531-43.

2. Botter SM, Neri D, Fuchs B. Recent advances in osteosarcoma. Curr Opin Pharmacol. 2014;16:15-23.

3. Luetke A, Meyers PA, Lewis I, Juergens H. Osteosarcoma treatment - Where do we stand? A state of the art review. Cancer Treat Rev. 2014;40(4):523-32.

4. Longhi A, Errani C, De Paolis M, Mercuri M, Bacci G. Primary bone osteosarcoma in the pediatric age: state of the art. Cancer Treat Rev. 2006;32(6):423-36.
5. Gorlick R, Bielack S. Osteosarcoma: Biology, diagnosis, treatment, and remaining challenges. En: Pizzo PA, Poplack DG, editores. Principles and practice of pediatric oncology, $6^{\text {th }}$ ed. Philadelphia: Wolters Kluwer Health/Lippincott Williams \& Wilkins; 2011. pp.1015.

6. Yamaguchi T, Toguchida J, Yamamuro T, Kotoura Y, Takada N, Kawaguchi N, et al. Allelotype analysis in osteosarcomas: frequent allele loss on 3q, 13q, 17p, and 18q. Cancer Res. 1992:52:2419-23.

7. Gorlick R, Khanna C. Osteosarcoma. J Bone Miner Res. 2010;25:683-91.

8. Jaffe N, Bruland OS, Bielack S. Pediatric and adolescent osteosarcoma. New York: Springer; 2009.

9. Bacci G, Bertoni F, Longhi A, Ferrari S, Forni C, Biagini R, et al. Neoadjuvant chemotherapy for high-grade central osteosarcoma of the extremity. Histologic response to preoperative chemotherapy correlates with histologic subtype of the tumor. Cancer. 2003;97:3068-75.

10. Huvos A. Bone tumors: diagnosis, treatment and prognosis. $2^{\text {nd }}$ ed. Philadelphia: WB Saunders; 1991.

11. A randomized trial of the European and American Osteosarcoma Study Group to optimize treatment strategies for resectable osteosarcoma based on histological response to pre-operative chemotherapy [Internet]. ISRCTN registry; 24/08/2004. Disponible en: http://www.isrctn.com/ISRCTN67613327?q=\&filters=conditionCategory: Cancer, recruitmentCountry:Switzerland, recruitmentCountry:Finland\&sort=\&offset=6\&totalResults $=7$ \&page $=1$ \&pageSize $=10$ \& search Type $=$ basic-search

12. Whelan J, Bielack S, Marina N, Smeland S, Whelan J, Bernstein N, et al. EURAMOS-1, an international randomised study for osteosarcoma: results from pre-randomisation treatment. Ann Oncol. 2015;26:407-14.

13. Smith MA, Ungerleider RS, Horowitz ME, Simon R. Influence of doxorubicin dose intensity on response and outcome for patients with osteogenic sarcoma and Ewing's sarcoma. J Natl Cancer Inst. 1991; $83: 1460-70$

14. Delepine N, Delepine G, Bacci G, Rosen G, Desbois JC. Influence of methotrexate dose intensity on outcome of patients with high grade osteosarcoma: Analysis of the literature. Cáncer. 1996;78:2127-35.

15. Bacci G, Ferrari S, Picci P, Zolezzi C, Gherlinzoni F, lantorno N, et al. Methotrexate serum concentration and histological response to multiagent primary chemotherapy for osteosarcoma of the limbs. J Chemother. 1996;8:472-8.

16. Lewis IJ, Weeden S, Machin D, Stark D, Craft AW. Received dose and dose-intensity of chemotherapy and outcome in nonmetastatic extremity osteosarcoma. J Clin Oncol. 2000;18:4028-37.

17. Longo DL, Duffey PL, DeVita VT Jr, Wesley MN, Hubbard SM, et al. The calculation of actual or received dose intensity: A comparison of published methods. J Clin Oncol. 1991;9:2042-51.

18. Miller TP, Dahlberg S, Weick JK, Files JC, Eyre HJ, Pendergrass KB Unfavorable histologies of non-Hodgkin's lymphoma treated with ProMACE-CytaBOM: A groupwide Southwest Oncology Group study. J Clin Oncol. 1990:8:1951-8.

19. Hryniuk W, Bush $\mathrm{H}$. The importance of dose intensity in chemotherapy of metastatic breast cancer. J Clin Oncol. 1984;2:1281-8.

20. Hryniuk W, Frei E III, Wright FA. A single scale for comparing dose-intensity of all chemotherapy regimens in breast cancer: summation dose-intensity. J Clin Oncol. 1998;16:3137-47.

21. Bacci G, Ferrari S, Delepine N, Bertoni F, Picci P, Mercuri M, et al. Predictive factors of histologic response to primary chemotherapy in osteosarcoma of the extremity: Study of 272 patients preoperatively treated with high-dose methotrexate, doxorubicin, and cisplatin. J Clin Oncol. 1998;16:658-63.

22. Bacci G, Forni C, Ferrari S, Longhi A, Bertoni F, Mercuri M, et al. Neoadjuvant chemotherapy for osteosarcoma of the extremity: Intensification of preoperative treatment does not increase the rate of good histologic response to the primary tumor or improve the final outcome. J Pediatr Hematol Oncol. 2003;25:845-53.

23. Lingling S, Yingjun L, Hengyuan Li, Jian Z, Binghao L, Zhaoming Y. Analysis of chemotherapy dosage and dosage intensity and survival outcomes of high-grade osteosarcoma patients younger than 40 years. Clinical Therapeutics. 2014;36:567-78.

24. Picci P, Bacci G, Campanacci M, Gasparini M, Pilotti S, Cerasoli S, et al. Histologic evaluation of necrosis in osteosarcoma induced by chemotherapy. Cancer. 1985; 56:1515-21.

25. Windebank KP, Spinetta JJ. Do as I sayor die: Compliance in adolescents with cancer. Pediatr Blood Cancer. 2008;50(5 Suppl):1099-100. 